\title{
Practices and Attitudes to Prevention of Travel-related Infectious Diseases in United Arab Emirates
}

\author{
Ghiath Ismayl ${ }^{1, *}$, Hamad Abdel Hadi ${ }^{2}$, Amal Hussein ${ }^{3}$, Mohamad Balchi ${ }^{1}$, Yaman Hukan ${ }^{1}$, Menatallah Mohamed ${ }^{1}$, Rana \\ Wehbe $^{1}$ \\ ${ }^{1}$ College of Medicine, University of Sharjah, Sharjah, UAE \\ ${ }^{2}$ Consultant Infectious Diseases, University Hospital Sharjah (UHS), Sharjah, UAE \\ ${ }^{3}$ Family \& Community Medicine \& Behavioral Sciences Department, College of Medicine, University of Sharjah, Sharjah, UAE
}

"Corresponding Author: Ghiath Ismayl, Medical Student (MBBS), M13-D Dorms, College of Medicine, University of Sharjah, Sharjah, UAE. Tel: 0097156761 8282, Email: U00033002@ sharjah.ac.ae

\begin{abstract}
Introduction: Among the United Arab Emirates (UAE) population more and more people now consider travelling abroad. This is potentially problematic because travelling enhances exposure between hosts and pathogens and so people that travel are putting their health at risk. This concern makes it necessary that public education is provided to inform people of the risks of travelling abroad so that such risks can be minimized. Guidelines and advice on travelling abroad are available and easily accessible but several studies have shown that travellers do not always follow such advice. In this study, the aim was to look into the practices and attitudes of UAE residents in relation to prevention of travel-related infectious diseases. Methods: A cross-sectional study was conducted from February to April 2015, in different emirates of the UAE. A self-administered anonymous questionnaire was developed based on material acquired from similar studies. The methodology applied quota sampling whereby adults above the age of 18 who'd travelled abroad in the past year were chosen from the seven emirates. The number of participants selected from each emirate was proportionate to the population size of each state.

Results: A total of 385 questionnaires were completed. A remarkable $70 \%$ of respondents indicated that they had not taken on any precautionary measures prior to travel. Of greater interest was that only $21 \%$ of participants had taken advice on health prior to travel, while the outstanding majority $79 \%$ reported that they had not taken advice. The most common source of advice had been taken from family and friends among those who had taken advice at $41 \%$, while only $15.4 \%$ had acquired it from specialized travel medicine clinics. High risk perception, spending more preparation time and travelling for longer durations were important factors that encouraged pretrial health consultation and undertook preventive measures.

Conclusion: This study revealed that UAE residents had not taken adequate measures to prevent travel related infectious diseases. Despite the limitations of this study, it still provides sufficient data to improve public health intervention directed at encouraging travellers to acquire pre travel health consultation.

Keywords: Travel Medicine, Public Health, Infectious Diseases
\end{abstract}

Article History: Received: 22 Nov. 2015; Accepted: 6 Feb. 2016; Online Published: 10 Apr. 2016

Cite this article as: Ismayl G, Hadi HA, Hussein A, Balchi M, Hukan Y, Mohamed M, et al. Practices and attitudes to prevention of travel-related infectious diseases in United Arab Emirates. Int J Travel Med Glob Health. 2016;4(1):13-8.

\section{Introduction}

Travelling for vacation and other reasons is a growing trend among populations worldwide. This increase in the rate of global travel over the past century, combined with environmental, commercial and demographic shifts facilitates the spread of established diseases as well as emerging infectious diseases. Movement of people increases exposure of hosts to pathogens and vectors that results in enhanced transmission of pathogens to different communities across the world [1]. However this can be controlled by adherence to suitable and adequate precautions prior to and during travel to minimize such risks of exposure to pathogens [2].

According to a study published by the national newspaper, a growing number of United Arab Emirates (UAE) subjects now make plans to travel abroad, especially during the summer season. Mediterranean countries in Europe, as well as countries in the Far East of the globe, are among the most popular destinations for people travelling from UAE [3]. Some of these destinations might be host to a variety of infections and South Eastern Asia in particular is reputed to be a hot spot for emerging infectious diseases [4].

Acquiring an infectious disease while travelling not only affects an individual but the harmful effect can extend to relatives, friends and the local community. Guidelines prepared by the Centre for Disease Control (CDC) indicate precautions that individuals should take prior to travel [5]. Strategies that should be followed in order to reduce the risk of acquiring travel-related infections include extensive pretravel preparation, obtaining up-to-date information on current health risks at destination, taking advice on behaviour modification to avoid exposure to pathogens while traveling, and using prophylactic agents, such as chemoprophylaxis and vaccinations; precautions that are based on a thorough risk assessment. Immunization is particularly important as it provides a potent, efficient and long-acting means of protection against certain pathogens [6].

Despite the fact that guidelines and advice are readily available and are easily accessible online, several studies have shown that travelers do not always take appropriate advice [7]. The public often tends to ignore the necessity of following preventive measures prior to travel. This was demonstrated in a study on Swedish travelers that found that only $40 \%$ and $3 \%$ reported adequate vaccine coverage prior to travel against Hepatitis A and Hepatitis B, respectively [8].

Epidemics and even pandemics such as avian flu, malaria, measles, and swine flu have caused wide spread panic in the world. Many of these infections are strongly associated with travel. Accordingly, the World Health Organization (WHO) issues regular relevant travel alerts. It is possible that 
incidence of travel-associated disease may be reduced by maximizing access to care and augmenting education in disease prevention. Moreover, since travellers are often unaware of risks associated with specific diseases while travelling, there remains demand and an urgent need for spreading awareness on important behavioral modifications and of the importance of preventive vaccinations [9].

Little is known about how travellers in UAE perceive health risks associated with travel and how they utilize precautionary measures and behave before traveling abroad to protect their health. This study was the first of its type in the UAE and it is crucial to assess whether the UAE population is taking adequate precautions to protect their health prior to travel, and to decide what effort should be taken by health authorities to protect travellers from the UAE against travel-related infections.

Building on all those previously mentioned facts; the objective of this study was to look into practices and attitudes followed by UAE residents towards prevention of travelrelated infectious diseases.

\section{Methods}

This was a descriptive cross-sectional study conducted in shopping centres and public areas in the UAE during the period February to April 2015. Inclusion criteria were UAE resident status aged 18 years and over, who had travelled in the preceding year. Participants who did not match these criteria or were not able to communicate in either English or Arabic were excluded.

A self-administered anonymous questionnaire was developed based on material acquired from similar studies conducted elsewhere but on the same topic. A pilot study was done on a sample of 25 subjects and then the questionnaire was modified and reviewed by the Family \& Community Medicine Department; it was determined as valid and reliable for the purpose of this study. The questionnaire was then distributed to a random sample $(n=385)$ of UAE residents. Quota sampling method was used; participants were chosen from the seven emirates in proportion to population size. Population sizes as follows were acquired from the 2005 census found on UAE Federal Competitiveness and Statistics Authority website; Abu Dhabi 34\% $(n=130)$, Dubai 32\% $(n=120)$, Sharjah 20\% $(n=75)$, Ras Al Khaimah 5\% $(n=20)$, Ajman 5\% $(n=20)$, Fujairah 3\% ( $n=15)$, Umm Al-Qaiwain 1\% $(n=5)$ [10].

Each participating individual was asked 20 questions on practices and attitudes to prevent of travel related infectious disease; these included seeking pre travel health advice and following necessary precautionary measures. All those that participated in interviews had provided written consent.

All personal information was treated with strict confidentiality. Data was entered electronically and analyzed using the SPSS Version 21 software. Data were expressed as frequencies and percentages unless otherwise stated. Chisquare analysis was used to test for difference in proportion between two or more groups for categorical variables. A p value less than 0.05 was considered to be statistically significant. After data analysis, the results were compared with those of similar studies to evaluate and make a conclusion.

A written informed consent was obtained from all participants. This study was approved by the Ethics and Research Committee (ERC) in Medical Colleges of Sharjah University.

\section{Results}

A total of 385 questionnaires were completed by individuals that matched inclusion criteria. The response rate was $100 \%$. Questionnaires were distributed almost equally among male and female participants, with $53.2 \%$ $(n=204)$ male respondents and $46.8 \%(n=181)$ female. $30.6 \%$ $(n=118)$ of respondents were less than 25 years of age, $30.9 \%$ $(n=119)$ were between 26 and 34 years of age, while $38.4 \%$ $(n=148)$ were aged more than or equal to 35 years.

Most respondents had travelled for the purpose of tourism $43.1 \%(n=166)$, or to visit family and friends $35.8 \%(n=138)$, while the remainder reported that the purpose of their travel was doing business or education $9.9 \%(n=38)$, or religious purposes $5.5 \%(n=21)$. It is noteworthy that the majority of respondents reported that they'd spent 7 days or less in preparation for travel $66.3 \%(\mathrm{n}=256)$, while only $8.1 \%$ $(\mathrm{n}=31)$ spent 29 days or more in preparation. Significantly, $74.5 \%(n=287)$ reported that this wasn't their first time travelling to the specific destination (Table 1).

Table 1. Variables associated with pretravel health advice practices and

\begin{tabular}{|c|c|c|c|}
\hline Variables & & Frequency & Percentage \\
\hline \multicolumn{4}{|l|}{ Gender: } \\
\hline & Male & 204 & $53.2 \%$ \\
\hline & Female & 181 & $46.8 \%$ \\
\hline \multicolumn{4}{|c|}{ Age group: } \\
\hline & $\leq 25$ & 118 & $30.6 \%$ \\
\hline & $26-34$ & 119 & $30.9 \%$ \\
\hline & $\geq 35$ & 148 & $38.4 \%$ \\
\hline \multicolumn{4}{|c|}{ Nationality: } \\
\hline & UAE & 77 & $20 \%$ \\
\hline & Arab Expat & 200 & $51.9 \%$ \\
\hline & Non-Arab & 108 & $28.1 \%$ \\
\hline \multicolumn{4}{|c|}{ Destination: } \\
\hline & Middle East & 122 & $31.7 \%$ \\
\hline & Europe & 89 & $23.1 \%$ \\
\hline & Asia & 88 & $22.9 \%$ \\
\hline & North Africa & 56 & $14.5 \%$ \\
\hline & North America & 24 & $6.2 \%$ \\
\hline & Sub Saharan Africa & 4 & $1 \%$ \\
\hline & Australia & 2 & $0.5 \%$ \\
\hline & Latin America & 0 & $0 \%$ \\
\hline \multicolumn{4}{|c|}{ Purpose: } \\
\hline & Tourism/Holiday & 166 & $43.1 \%$ \\
\hline & Visit Family/Friends & 138 & $35.8 \%$ \\
\hline & Business/Education & 38 & $9.9 \%$ \\
\hline & Religious (Pilgrimage) & 21 & $5.5 \%$ \\
\hline & Others & 22 & $5.7 \%$ \\
\hline \multicolumn{4}{|c|}{ Duration: } \\
\hline & $\leq 7$ Days & 108 & $28.1 \%$ \\
\hline & $8-14$ Days & 111 & $28.8 \%$ \\
\hline & $15-28$ Days & 56 & $14.5 \%$ \\
\hline & $\geq 29$ Days & 110 & $28.6 \%$ \\
\hline \multicolumn{4}{|c|}{ Time spent preparing: } \\
\hline & $\leq 7$ Days & 256 & $66.3 \%$ \\
\hline & $8-14$ Days & 68 & $17.8 \%$ \\
\hline & $15-28$ Days & 30 & $7.8 \%$ \\
\hline & $\geq 29$ Days & 31 & $8.1 \%$ \\
\hline \multicolumn{4}{|c|}{$1^{\text {st }}$ time to visit destination: } \\
\hline & Yes & 98 & $25.5 \%$ \\
\hline & No & 287 & $74.5 \%$ \\
\hline \multicolumn{4}{|c|}{$\begin{array}{l}\text { Perceived risk of acquiring travel } \\
\text { related infection at destination: }\end{array}$} \\
\hline & High & 41 & $10.5 \%$ \\
\hline & Low & 257 & $66.8 \%$ \\
\hline & I don't know & 87 & $22.7 \%$ \\
\hline Total & & 385 & $100 \%$ \\
\hline
\end{tabular}

Most travellers included in the sample perceived the risk of acquiring a travel related infection at their destination as low $66.8 \%(n=257)$, with only $10.50 \%(n=41)$ perceiving a high risk of infection at their destination. As a result, a remarkable 
$70 \%(n=270)$ of respondents indicated that they did not seek any precautionary measures prior to their trip. The most common precautionary measure was to take medication, reported by $13 \%(n=50)$ of the sample (Figure 1$)$. Of a greater interest was that only $21 \%(n=81)$ sought advice on health for travel prior to their trip, while the outstanding majority $79 \%(n=304)$ said they had not taken advice. Of those who had taken advice, a high percentage of $92.4 \%$ $(\mathrm{n}=75 / 81)$ adhered to the advice they'd received. The most common source of advice was from family and friends $41 \%$ $(n=33 / 81)$, followed by the Internet $35.9 \%(n=29 / 81)$, and general practitioners $29.1 \%(n=24 / 81)$. Shockingly, only $15.4 \%(n=12 / 81)$ took advice on health from specialized travel medicine clinics (Figure 2).

However, those who had not taken advice on travel health gave the justification that they perceived they were not at risk $43.2 \% \quad(\mathrm{n}=131$ / 304), already knew what to do $37.2 \% \quad(n=113 / 304)$, didn't know that they should take advice 15\% $(\mathrm{n}=46 / 304)$, or were too busy to do so $4.6 \%(n=14 / 304)$ (Figure 3).

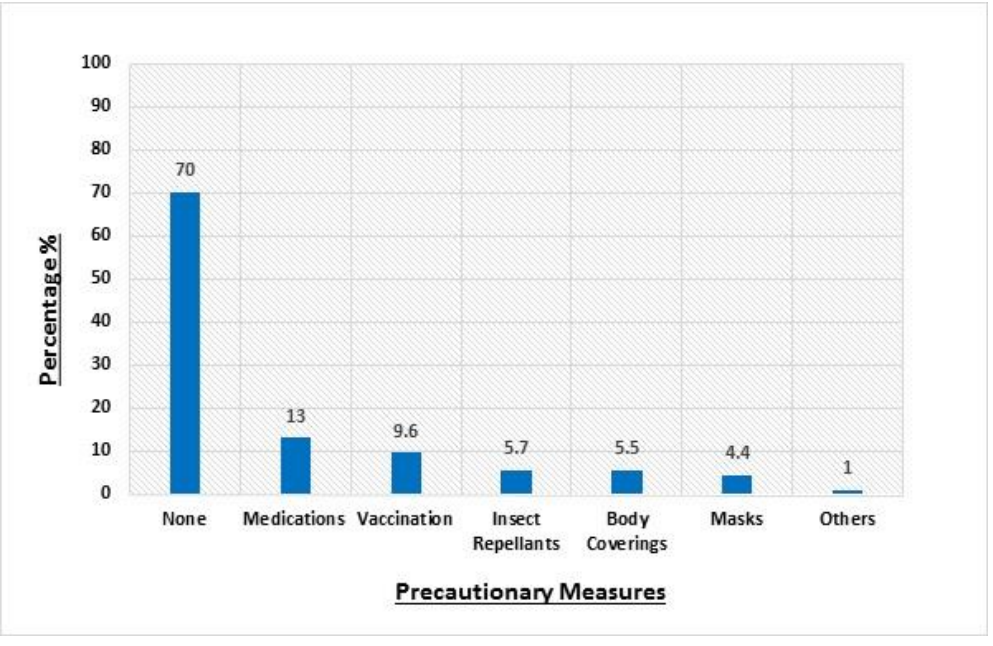

Figure 1. The proportion of different precautionary measures undertaken prior to travelling: The respondants were permitted to chose more than one option The majority did not take on any precautionary measures

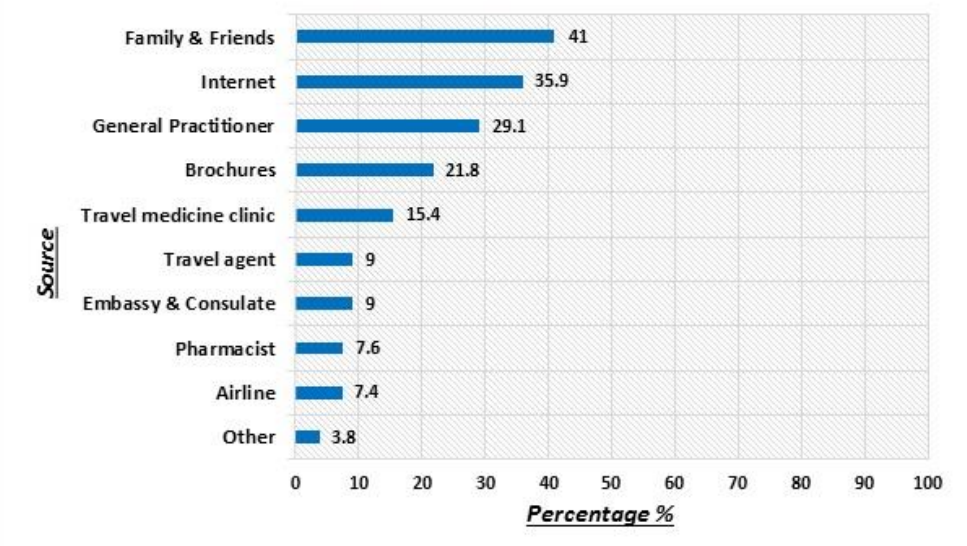

Figure 2. Source of travel health advice for those who sought it. The respondants were permitted to chose more than one option. Only $15.4 \%$ depended on travel medicine clinics



Figure 3. Reasons for not seeking travel health advice for those who did NOT seek it 
It is important to document that on Pearson Chi-Square analysis, it was noted that UAE nationals were more likely to seek pre travel health advice than both Arab and non-Arab expatriates $(p=0.006)$. It was also observed that females, participants who spent more preparation time prior to travel and those who went on longer duration trips were more likely to take preventive measures $(\mathrm{p}<0.001, \mathrm{p}=0.03, \mathrm{p}=0.006$ respectively). Respondents who perceived the risk of infection at their destination to be low were less likely to seek pre travel consultation or precautionary measures $(\mathrm{p}<0.001$ and $\mathrm{p}=0.003$ ). Travellers for religious purposes were the most likely to seek pre travel advice and preventive measures $(p<0.001$ and $p=0.003)$. Surprisingly those who were visiting a destination for the first time were less likely to take precautionary measures $(\mathrm{p}=0.02)$. Correlation with the destination was found to be significant (p less than 0.05), but it was determined as non-reliable by the Family \& Community Medicine Department due to the small number of participants in some choices of that section (Table 2).

Lastly, it is important to mention that, when asked about their preferred method of receiving pre travel health advice in the future, respondents chose the Internet as the preferred method $44.9 \% \quad(n=173)$, closely followed by physicians $38.4 \%(n=148)$, and then family and friends $36.6 \%(n=141)$. Again, only a small number of participants chose travel medicine clinicians as the preferred route for acquiring pre travel health advice $13.6 \%(n=52)$.

Table 2. Impact of different variables on seeking pretravel health advice and acquiring preventive measures. A Pearson Chi-Square is presented for each variable. A p value less than 0.05 was considered to be statistically significan

\begin{tabular}{|c|c|c|c|c|}
\hline \multirow{2}{*}{ Variable } & \multicolumn{2}{|c|}{ Pretravel Health Advice } & \multicolumn{2}{|c|}{ Preventive Measures } \\
\hline & Yes [n $(\%)]$ & No $[\mathrm{n}(\%)]$ & Yes [n (\%)] & No [n (\%)] \\
\hline \multicolumn{5}{|l|}{ Gender: } \\
\hline Male & $37(18 \%)$ & $167(82 \%)$ & $41(20 \%)$ & $163(80 \%)$ \\
\hline Female & $44(24 \%)$ & $137(76 \%)$ & $74(41 \%)$ & $107(59 \%)$ \\
\hline Pearson Chi-Square & $p=0.12$ & & $p<0.001$ & \\
\hline \multicolumn{5}{|l|}{ Age group: } \\
\hline$\leq 25$ & $19(16 \%)$ & $99(84 \%)$ & $28(24 \%)$ & $90(76 \%)$ \\
\hline $26-34$ & $30(25 \%)$ & $89(75 \%)$ & $43(36 \%)$ & $76(64 \%)$ \\
\hline$\geq 35$ & $32(22 \%)$ & $116(78 \%)$ & $44(30 \%)$ & $104(70 \%)$ \\
\hline Pearson Chi-Square & $p=0.17$ & & $p=0.11$ & \\
\hline \multicolumn{5}{|l|}{ Nationality: } \\
\hline UAE & $27(35 \%)$ & $50(65 \%)$ & $28(36 \%)$ & $49(64 \%)$ \\
\hline Arab Expat & $34(17 \%)$ & $166(83 \%)$ & $56(28 \%)$ & $144(72 \%)$ \\
\hline Non-Arab & $20(19 \%)$ & $88(81 \%)$ & $31(29 \%)$ & $77(71 \%)$ \\
\hline Pearson Chi-Square & $p=0.006$ & & $p=0.38$ & \\
\hline \multicolumn{5}{|l|}{ Destination: } \\
\hline Europe & $15(17 \%)$ & $74(83 \%)$ & $17(19 \%)$ & $72(81 \%)$ \\
\hline Asia & $20(23 \%)$ & $68(77 \%)$ & $31(35 \%)$ & $57(65 \%)$ \\
\hline North Africa & $8(14 \%)$ & $48(86 \%)$ & $15(27 \%)$ & $41(73 \%)$ \\
\hline North America & $9(38 \%)$ & $15(62 \%)$ & $12(50 \%)$ & $12(50 \%)$ \\
\hline Sub Saharan Africa & $3(75 \%)$ & $1(25 \%)$ & $3(75 \%)$ & $1(25 \%)$ \\
\hline Australia & $0(0 \%)$ & $2(100 \%)$ & $0(0 \%)$ & $2(100 \%)$ \\
\hline Latin America & 0 & 0 & 0 & 0 \\
\hline Pearson Chi-Square & $p=0.02$ & & $p=0.01$ & \\
\hline \multicolumn{5}{|l|}{ Purpose: } \\
\hline Tourism/Holiday & $28(17 \%)$ & $138(83 \%)$ & $47(28 \%)$ & $119(72 \%)$ \\
\hline Visit Family/Friends & $20(15 \%)$ & $118(85 \%)$ & $34(25 \%)$ & $104(75 \%)$ \\
\hline Business/Education & $13(34 \%)$ & $25(66 \%)$ & $10(26 \%)$ & $28(74 \%)$ \\
\hline Religious (Pilgrimage) & $14(67 \%)$ & $7(33 \%)$ & $14(67 \%)$ & $7(33 \%)$ \\
\hline Others & $6(27 \%)$ & $16(73 \%)$ & $10(45 \%)$ & $12(55 \%)$ \\
\hline Pearson Chi-Square & $p<0.001$ & & $p=0.003$ & \\
\hline \multicolumn{5}{|l|}{ Duration: } \\
\hline$\leq 7$ Days & $23(21 \%)$ & $85(79 \%)$ & $23(21 \%)$ & $85(79 \%)$ \\
\hline$\geq 29$ Days & $29(26 \%)$ & $81(74 \%)$ & $46(42 \%)$ & $64(58 \%)$ \\
\hline Pearson Chi-Square & $p=0.16$ & & $p=0.006$ & \\
\hline \multicolumn{5}{|l|}{ Time spent preparing: } \\
\hline$\leq 7$ Days & $51(20 \%)$ & $205(80 \%)$ & $64(25 \%)$ & $192(75 \%)$ \\
\hline $8-14$ Days & $17(25 \%)$ & $51(75 \%)$ & $28(41 \%)$ & $40(59 \%)$ \\
\hline 15 - 28 Days & $3(10 \%)$ & $27(90 \%)$ & $13(43 \%)$ & $17(57 \%)$ \\
\hline$\geq 29$ Days & $10(32 \%)$ & $21(68 \%)$ & $10(32 \%)$ & $21(68 \%)$ \\
\hline Pearson Chi-Square & $p=0.17$ & & $p=0.03$ & \\
\hline \multicolumn{5}{|l|}{$1^{\text {st }}$ time to visit destination: } \\
\hline Yes & $20(20 \%)$ & $78(80 \%)$ & $20(20 \%)$ & $78(80 \%)$ \\
\hline No & $61(21 \%)$ & $226(79 \%)$ & $95(33 \%)$ & $192(67 \%)$ \\
\hline Pearson Chi-Square & $p=0.89$ & & $p=0.02$ & \\
\hline \multicolumn{5}{|c|}{$\begin{array}{l}\text { Perceived risk of acquiring travel related } \\
\text { infection at destination: }\end{array}$} \\
\hline High & $21(51 \%)$ & $20(49 \%)$ & $22(54 \%)$ & $19(46 \%)$ \\
\hline Low & $47(18 \%)$ & $210(82 \%)$ & $72(28 \%)$ & $185(72 \%)$ \\
\hline I don't know & $13(15 \%)$ & $74(85 \%)$ & $21(24 \%)$ & $66(76 \%)$ \\
\hline Pearson Chi-Square & $p<0.001$ & & $p=0.003$ & \\
\hline Total & $81(21 \%)$ & $304(79 \%)$ & $115(30 \%)$ & $270(70 \%)$ \\
\hline
\end{tabular}


Ismayl et al. Travel-Related Infectious Diseases

Table 3. Comparison between different studies in Pretravel health advice acquisition and Travel medicine clinics utilization

\begin{tabular}{|c|c|c|c|c|c|c|c|c|c|}
\hline Study & UAE & Johannesburg[11] & Swedish $[8]$ & European[12] & American[13] & Australian[14] & Korean[15] & Qatari[16] & Omani[17] \\
\hline $\begin{array}{l}\text { Pretravel health } \\
\text { advice acquisition }\end{array}$ & $21 \%$ & $86 \%$ & $60 \%$ & $52.1 \%$ & $36 \%$ & $31 \%$ & $24 \%$ & $19 \%$ & $22.5 \%$ \\
\hline $\begin{array}{l}\text { Travel medicine } \\
\text { clinics utilization }\end{array}$ & $15.4 \%$ & $25 \%$ & $30 \%$ & $35.3 \%$ & $10 \%$ & $4 \%$ & $0 \%$ & $2.2 \%$ & NA \\
\hline
\end{tabular}

\section{Discussion}

This study demonstrated that $21 \%$ of respondents sought pre travel health advice and $30 \%$ undertook precautionary measures prior to travel. Those figures are considerably low compared to figures determined by other studies on the same topic. For instance, the rate of taking pre travel health advice and consultation was $86 \%$ in a Johannesburg study [11], $60 \%$ in a Swedish study [8], 52.1\% in a European study [6], 36\% in an American study [12], 31\% in an Australian study [13] $24 \%$ in Korean travellers [14], 19\% in Qatar [15] and 22.5\% in Oman [16].

The main reasons behind the previously mentioned findings seem to be that travellers either perceived the risk to be low or non-existent at their destination, or held the belief that they were already aware of the instructions to protect their health. This could be explained by the fact that the majority of subjects in our sample, which in reality reflected the demographic composition of the UAE society as nonEmirati and so most commonly travelled to their country of origin during vacation. This could also explain why UAE nationals were determined as the most likely to seek pre travel health advice, as they were leaving their home country. Another explanation for these findings could be shortness of duration spent in preparation for travel. As illustrated in this study, those who spent less time preparing were less likely to take preventive measures. Nevertheless, compared to other similar studies, this study determined figures that were significantly low, so a need to address this concern effectively was determined as essential.

Risk perception is an important factor in self-protection against risk of contracting disease while travelling [17], as it serves as a guide to appropriate attitude and practice related to health prior to travel. It was noted in our study that low risk perception (43.2\%) was the most common reason reported by participants for not seeking pre travel health advice.

Of those who sought pre travel advice, $41 \%$ acquired it from friends \& family and $35.9 \%$ relied on the Internet as a source of advice, while only $15.4 \%$ of respondents depended on a travel medicine clinic. When participants were asked in general about their preferred source of advice, only $13.6 \%$ chose a travel medicine clinic. Nevertheless, utilization of a travel medicine clinic in the UAE appears to be better than those reported in American [12], Australian [13], Korean [14] and Qatari [15] studies, but less than that reported in studies on Johannesburg [11], Sweden [8] and Europe [6]. Seeking advice on health from friends and families is potentially misleading and could put health at risk because as these sources might not hold the necessary knowledge and expertise. Even health professionals, not to mention individuals working outside the health sector, could provide inappropriate pre travel health advice [18-20]. Thus, it is necessary to establish specialized travel clinics in society and to encourage travellers to use them. Similar conclusions were reached in Australian [13], Korean [14] and Qatari [15] studies, which highlighted a lack of awareness about the importance of travel medicine clinics in society and reported a need to establish more travel clinics and to inspire the community to use them.

Regarding Pearson correlations, it was observed that travellers for religious purposes were the most likely to seek pre travel advice and to take preventive measures. This result was also determined in an Omani study [16], which was most probably because vaccination was mandatory prior to taking the pilgrimage to Mecca, Saudi Arabia (Islamic religious ritual), which is a common destination for religious purposes from the UAE and other countries in the region. Also, participants visiting a destination for the first time were less likely to undertake precautionary measures. This could be explained by the idea that participants who had visited a destination before were more aware of preventive measures required for a particular destination, and thus were prepared to take such measures in travel to that destination. Being female was a good predictor of taking preventive measures. A similar conclusion was reached in the Omani study, which could be justified by the fact that women in general were more cautious about their health and visited general practitioners more frequently than did men [16].

When comparing the precautionary measures and pre travel health advice variables, it was observed that those who sought pre travel advice were much more likely to acquire precautionary measures $(\mathrm{p}<0.001)$. This illustrates the significance and necessity of obtaining travel health consultation prior to travel.

This study had several limitations:

Assessment of the knowledge of travellers was overlooked and educational level was not determined for participants; these factors would be beneficial for consideration of pre travel health advice and precautionary measures. Also, more detailed information could have been obtained regarding attitudes and practices.

\section{Conclusion}

This study revealed that UAE residents did not adapt appropriate adequate practice and attitude in prevention of travel-related infectious diseases. Despite the limitations of this study, it has provided sufficient data to help improve public health interventions directed at encouraging travellers to take pre travel health consultation. Awareness campaigns and promotion activities should be established to educate people in UAE of the importance of seeking pre travel health advice and to take appropriate precautionary measures, as well as to highlight the need to consult specialized travel medicine clinics. All of which are essential in order for travellers to stay healthy while abroad and on their return.

\section{Recommendations}

We recommend future studies to be directed towards the knowledge of the UAE population about travel-related infectious diseases and travel health services available in the UAE, as there is a possibility that lack of knowledge and awareness could be the reason behind the low numbers seeking pre travel consultation and preventive measures. 


\section{Consent}

A written informed consent was obtained from all the participants. They are available for review by the authors of this article.

This study has been reviewed and approved by the Ethics and Research Committee (ERC) in Medical Colleges of Sharjah University that operates according to the Good Clinical Practice (GCP) guidelines.

\section{Acknowledgements}

The authors would like to thank the Family \& Community Medicine Department, College of Medicine, University of Sharjah, UAE.

\section{Authors' Contributions}

GI reviewed the literature, wrote the introduction, results and discussion, set the design and wrote the first draft and the final draft. HA \& AH supervised the research process, helped set the study design and plan. MB \& YH prepared the results, read the manuscript and made significant modifications in the manuscript. MM \& RW wrote the methodology and conclusion, read the manuscript and made significant modifications in the manuscript. All authors played a significant role in data collection, entry and analysis. All authors read and approved the final manuscript.

\section{Financial Disclosure}

The authors declare that they have no competing interests. None of the authors of this paper has a financial or personal relationship with people in organizations that could inappropriately influence or bias the content of the paper.

\section{Funding/Support}

No honorarium, grants, or other forms of payment were given to anyone to produce the manuscript.

\section{References}

1. Baer A, Libassi L, Lloyd JK, Benoliel E, Brucker R, Jones MQ, et al. Risk factors for infections in international travelers: an analysis of travel-related notifiable communicable diseases. Travel Med Infect Dis. 2014;12(5):525-33

2. Gezairy HA. Travel epidemiology: WHO perspective. Int J Antimicrob Agents. 2003;21(2):86-8.

3. Hanif N. More people opting to leave UAE on summer breaks: The National; 2013 [2013, July 1]. Available from: http://www.thenational.ae.

4. Horby PW, Pfeiffer D, Oshitani H. Prospects for emerging infections in East and southeast Asia 10 years after severe acute respiratory syndrome. Emerg Infect Dis. 2013;19(6):853-60.

5. Prevention CfDCa. Travel Health Notices 2014 [2014, November 13]. Available from: http://wwwnc.cdc.gov/travel/notices.

6. Van Herck K, Van Damme P, Castelli F, Zuckerman J, Nothdurft H, Dahlgren AL, et al. Knowledge, attitudes and practices in travelrelated infectious diseases: the European airport survey. J Travel Med. 2004;11(1):3-8

7. Prazuck T, Semaille C, Defayolle M, Bargain P, Clerel M, Lafaix C, et al. [Vaccination status of French and European travelers: a study of 9,156 subjects departing from Paris to 12 tropical destinations] Rev Epidemiol Sante Publique. 1998;46(1):64-7.

8. Dahlgren AL, DeRoo L, Steffen R. Prevention of travel-related infectious diseases: knowledge, practices and attitudes of Swedish travellers. Scand J Infect Dis. 2006;38(11-12):1074-80.

9. Memish ZA, Al-Tawfiq JA, Assiri A, Mohammed M, Bamgboye EA, Alhakeem R. Epidemiology of mumps and rubella in the Kingdom of Saudi Arabia: 2009-2011--Implications for immigration and travel. Travel Med Infect Dis. 2015;13(3):261-2.

10. Authority FCaS. 2014 [2010, December 25]. Available from: http://www.fcsa.gov.ae.

11. Toovey S, Jamieson A, Holloway M. Travelers' knowledge, attitudes and practices on the prevention of infectious diseases: results from a study at Johannesburg International Airport. J Travel Med. 2004;11(1):16-22.

12. Hamer DH, Connor BA. Travel health knowledge, attitudes and practices among United States travelers. J Travel Med. 2004;11(1):23-6.

13. Wilder-Smith A, Khairullah NS, Song JH, Chen CY, Torresi J. Travel health knowledge, attitudes and practices among Australasian travelers. J Travel Med. 2004;11(1):9-15.

14. Yoo YJ, Bae GO, Choi JH, Shin HC, Ga H, Shin SR, et al. Korean travelers' knowledge, attitudes, and practices regarding the prevention of malaria: measures taken by travelers departing for India from Incheon International Airport. J Travel Med. 2007;14(6):381-5.

15. Al-Hajri M, Bene A, Eljack I, Balbaid O. Travellers Knowledge, Attitudes and Practices on the Prevention of Infectious Diseases: Qatar-Doha International Airport Study. Middle East J Family Med. $2011 ; 9(9)$

16. Al-Abri SS, Abdel-Hady DM, Al-Abaidani IS. Knowledge, attitudes, and practices regarding travel health among Muscat International Airport travelers in Oman: Identifying the gaps and addressing the challenges. J Epidemiol Glob Health. 2016;pii: S22106006(15):30123-4.

17. Chen CM, Tsai JS, Chen SH, Lee HT. Knowledge, attitudes, and practices concerning infection control among travelers between Taiwan and mainland China. Asia Pac J Public Health 2011;23(5):712-20.

18. Grabowski P, Behrens RH. Provision of health information by British travel agents. Trop Med Int Health. 1996;1(5):730-2

19. Keystone JS, Kozarsky PE, Freedman DO. Internet and computerbased resources for travel medicine practitioners. Clinical infectious diseases : an official publication of the Infectious Diseases Society of America. 2001;32(5):757-65

20. Provost S, Gaulin C, Piquet-Gauthier B, Emmanuelli J, Venne S, Dion $\mathrm{R}$, et al. Travel agents and the prevention of health problems among travelers in Quebec. J Travel Med. 2002;9(1):3-9. 